\title{
New oxyuroid nematodes of the genera Ichthyouris and Spinoxyuris from South American freshwater fishes
}

\author{
František Moravec $^{1}$ and Vernon E. Thatcher ${ }^{2}$ \\ ${ }^{1}$ Institute of Parasitology, Academy of Sciences of the Czech Republic, Branišovská 31, 37005 České Budějovice, Czech \\ Republic; \\ ${ }^{2}$ Departamento de Zoologia, Universidade Federal do Paraná, Curitiba, Paraná and Research Fellow of the Conselho Nacional de \\ Pesquisas (CNPq), Brasília, Brazil
}

Key words: Ichthyouris, Spinoxyuris, Nematoda, Oxyuroidea, parasite, freshwater fish, Cichlasoma, Myleus, Brazil, French Guiana

\begin{abstract}
Three hitherto unknown oxyuroid nematode species of the family Pharyngodonidae are described from the intestine of South American freshwater fishes, two of them being established as species new to science: Spinoxyuris annulata sp. $\mathrm{n}$. from Myleus ternetzi (Norman) (Serrasalmidae) from French Guiana (Sinnamary River) and Ichthyouris ovifilamentosa sp. $\mathrm{n}$. from Cichlasoma sp. (Cichlidae) from Amazonas (Negro River, São Gabriel da Cachoeira), Brazil. A third species, recovered from the same host as the latter (Cichlasoma sp.), was identified only as Ichthyouris sp. because of the absence of the male, although it probably also represents a new species. S. annulata differs from the only other congeneric species, S. oxydoras Petter, 1994, mainly in the absence of egg filaments, the location of an unpaired postanal papilla in the male, a distinctly longer spicule, and in an approximately double length of the body. Ichthyouris ovifilamentosa is closest to I. ro Inglis, 1962, differing from it principally in the structure of the cephalic end, the position of the excretory pore, and in the presence of filamented eggs. Ichthyouris sp. females differ from their congeners mainly in a characteristic structure of the cephalic end, the extent of lateral alae and the shape of their posterior ends, and in the character of egg filaments.
\end{abstract}

Oxyuroid nematodes are infrequent intestinal parasites of fishes and only a few pharyngodonid genera are known to occur in freshwater and marine fishes in tropical and subtropical regions. Most of them are parasites of neotropical fishes in South America, from where a total of 11 species belonging to seven genera have so far been described (Moravec 1998). The majority of species of the genera Brasilnema Moravec, Kohn et Fernandes, 1992, Cosmoxynema Travassos, 1949, Cosmoxynemoides Travassos, 1949, Ichthyouris Inglis, 1962, Parasynodontisia Moravec, Kohn et Fernandes, 1992 and Travnema Pereira, 1938 are known from fishes in Brazil (Pereira 1938, Travassos 1949, Fernandes et al. 1983, Moravec et al. 1992a, b), whereas only two species of Parasynodontisia and Spinoxyuris Petter, 1994 are known from Paraguay (Petter 1994), and one species of Ichthyouris from Guyana (Inglis 1962).

During the examination of some freshwater fishes from Amazonia in Brazil and from French Guiana carried out by the second author in 1989, specimens of three previously undescribed oxyuroid species were collected from the intestine of Cichlasoma sp. and Myleus ternetzi (Norman). These are described herein.

\section{MATERIALS AND METHODS}

The nematode specimens were fixed and preserved in $70 \%$ ethanol and cleared with glycerine for light microscopy examination. Drawings were made with the aid of a Zeiss microscope drawing attachment. For examination by scanning electron microscopy, the nematodes were postfixed in $1 \%$ osmium tetroxide, dehydrated through graded ethanol, critically point dried, and sputter-coated with gold. They were examined with a JEOL JSM-6300 scanning electron microscope at an accelerating voltage of $15 \mathrm{kV}$. Measurements are in micrometres, unless otherwise stated, as the range followed by a single type specimen in parentheses. The specimens were deposited (in vials with $70 \%$ ethanol) in the Instituto Nacional de Pesquisas da Amazônia (INPA), Manaus, Brazil; University of Nebraska State Museum (UNSM), Lincoln, Nebraska, USA; and in the Institute of Parasitology, Academy of Sciences of the Czech Republic (IPCAS), České Budějovice, Czech Republic.

\section{RESULTS}

OXYUROIDEA Cobbold, 1864

Pharyngodonidae Travassos, 1919

\section{Spinoxyuris annulata $\mathrm{sp} . \mathrm{n}$.}

Figs. 1, 2

General: Small nematodes, males markedly smaller than females. Body fusiform, cuticle with distinct transverse striations. Well-developed lateral alae initiating anteriorly somewhat anterior to level of nerve ring and extending posteriorly to level of anus in females and to short distance posterior to genital cone in males; posterior ends of alae forming marked, 


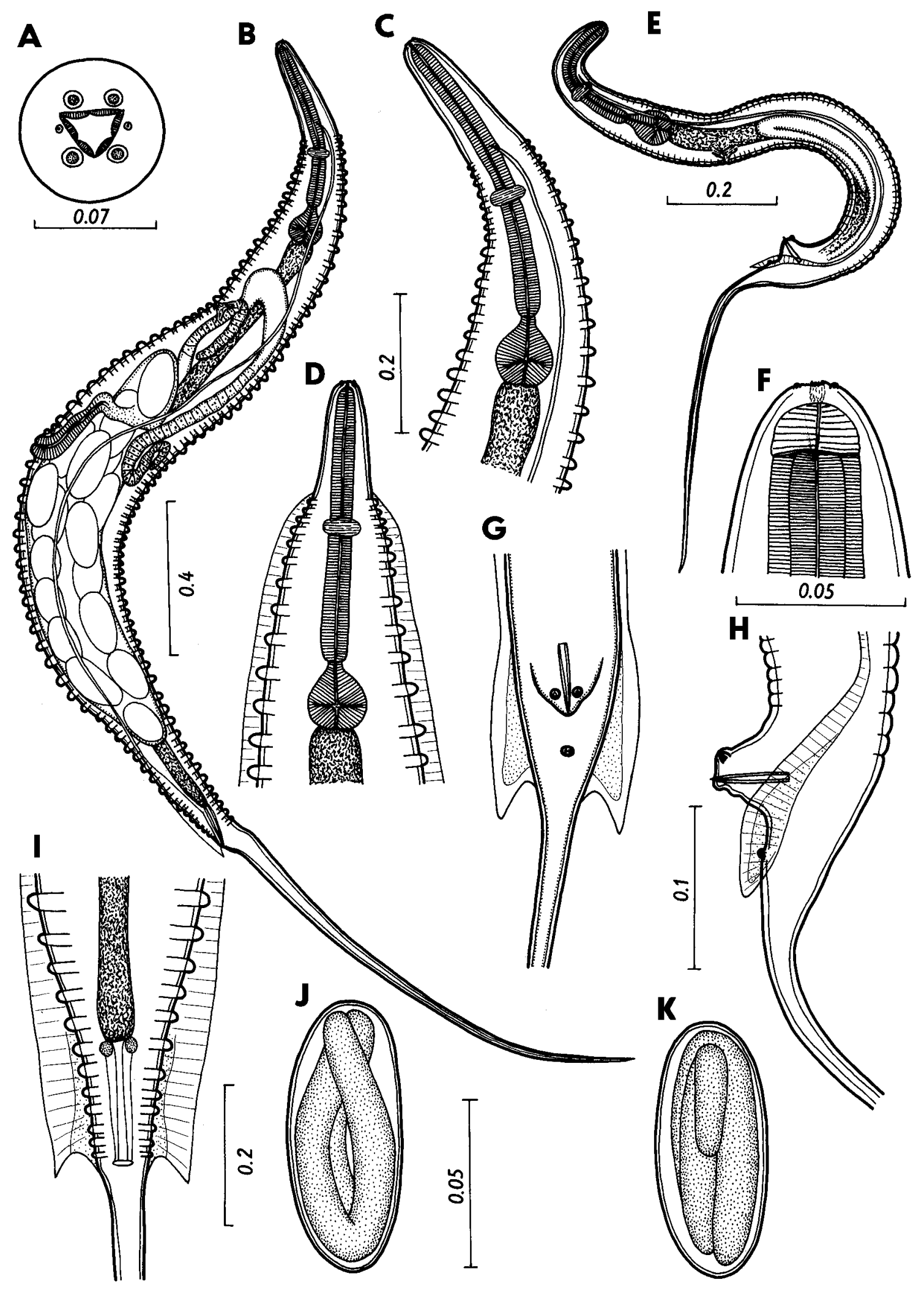

Fig. 1. Spinoxyuris annulata sp. n. A - cephalic end of female, apical view; B - gravid female, general view; $\mathbf{C}$, D - anterior end of female, lateral and dorsoventral views; $\mathbf{E}$ - male, general view; $\mathbf{F}$ - cephalic end of female, lateral view; $\mathbf{G}, \mathbf{H}$ - cloacal region of male, ventral and lateral views; $\mathbf{I}$ - anal region of female, ventral view; $\mathbf{J}, \mathbf{K}$ - mature egg. Scales in mm. 

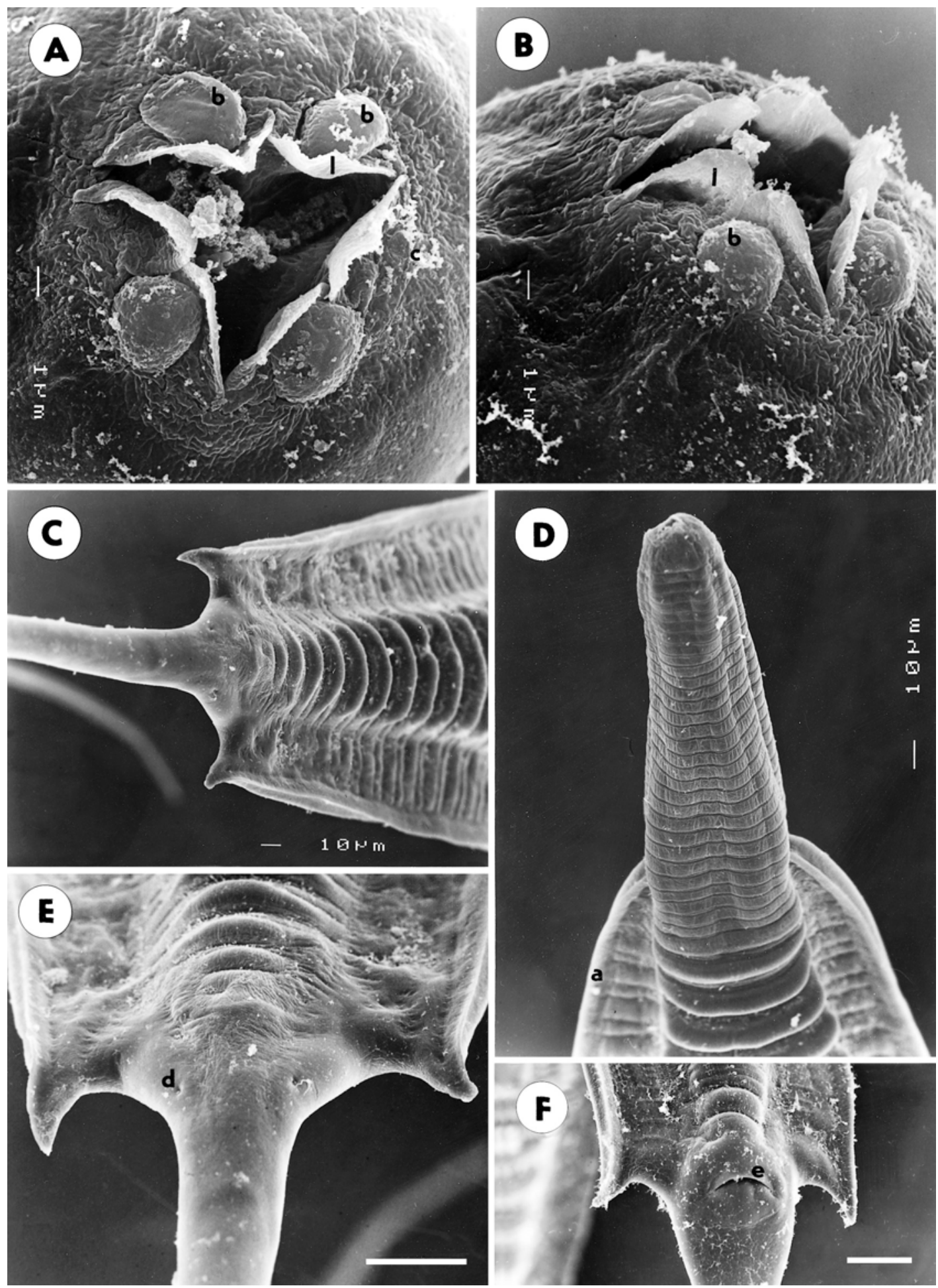

Fig. 2. Spinoxyuris annulata sp. n., scanning electron micrographs of female. A, B - cephalic end, apical and sublateral views; $\mathbf{C}$ - caudal region, dorsal view; D - anterior end of body, ventral view; $\mathbf{E}, \mathbf{F}$ - caudal region, dorsal and ventral views (scale bars = $30 \mu \mathrm{m})$. a - lateral ala; b - cephalic papilla; c - amphid; $\mathrm{d}$ - phasmid; e - anus; 1 - cephalic lamella.

posteriorly directed spines. Oral aperture triangular, surrounded by six anteriorly rounded cuticular lamellae. Four large submedian spherical cephalic papillae and pair of small lateral amphids present. Oesophagus formed by long, almost cylindrical corpus with slightly outlined short "pharynx", short isthmus and welldeveloped bulb provided with sclerotised apparatus. Nerve ring situated in about mid-length of corpus, 
excretory pore at some distance (equal to $37-40 \%$ of oesophagus length in males and $41-54 \%$ of that in gravid females) posterior to oesophagus. Tail of both sexes forming very long, slender caudal spike.

Male (2 specimens; measurements of holotype in parentheses): Length of body including caudal spike 1,850-1,945 (1,945), maximum width 109-122 (109). Distinct striation of body starting at nerve ring level and ending at level of genital cone; striae 9-12 (9-12) long and 3-6 (3) high. Lateral alae distinctly broader at caudal region, ending in large spines. Entire oesophagus 378-379 (379) long; corpus including "pharynx" 285 (285) long and 27-33 (27) wide, "pharynx" 6-9 (9) long; isthmus 18-21 (18) long and 18-24 (18) wide; and bulb $72-75$ (75) long and 69-72 (69) wide. Nerve ring and excretory pore 177-186 (177) and 517-530 (517), respectively, from anterior extremity. Genital cone truncated, 24-36 (36) high, bearing pair of small preanal papillae immediately anterior to cloacal opening. Single median postanal papilla situated somewhat posterior to genital cone, 63-66 (63) from cloacal aperture. Spicule simple, well sclerotised, 66-72 (66) long and 6-7 (7) wide, with pointed distal tip. Entire tail 653-721 (653) long; its broader anterior part 95 (95) long, length of slender caudal spike 558-653 (558). Tail forming 34$39 \%$ (34\%) of entire length of body.

Female (10 gravid and 1 nongravid specimens; measurements of allotype in parentheses, those of 1 nongravid female in brackets): Body distinctly fusiform, broadest at level of vulva; body length including caudal spike of gravid specimens 3,998-4,352 (3,998) [2,557], maximum width 340-408 (340) [177]. Striation of body conspicuous, starting anteriorly short distance anterior to nerve ring, approximately at same level as lateral alae, and ending at level of anus; striae 30-36 (30-36) [9-15] long and 6-24 (6-21) [6] high in middle part of body, diminishing somewhat toward anterior and posterior ends of body. Lateral alae distinctly broader at rectal region of body; their width at anterior part of body 30 (30) [not measured], at rectal region 63 (63) [not measured]; length of posterior spines 60 (60) [not measured]. Entire oesophagus 516-597 (597) [492] long; corpus including "pharynx" 411-486 (486) [390] long and 36-42 (42) [36] wide, "pharynx" 9 (9) [9] long; isthmus 12-15 (15) [18] long and 21-27 (27) [18] wide; bulb 84-96 (96) [84] long and 99-102 (102) [90] wide. Intestine narrow, straight. Nerve ring and excretory pore 195-303 (303) [198] and 734-857 (843) [558], respectively, from anterior extremity. Vulva situated 1,292$1,469(1,469)$ [857] from anterior end of body, vulvar lips somewhat elevated in largest females. Muscular vagina short, directed anteriorly from vulva. Reproductive apparatus didelphic, both ovaries forming coils situated anteriorly to vulva. Uteri filled with eggs occupying middle third of body. Mature eggs elongate oval, thin-walled, containing already formed larva; size of eggs 150-180 × 66-84 (156-165 × 78-84) [-]. Entire tail 1,237-1,441 $(1,237)$ [939] long; its broader anterior part 54-68 (54) [41] long, length of slender caudal spike $1,183-1,387(1,183)$ [898]. Tail forming 31-33\% (31\%) [37\%] of entire length of body. Pair of small phasmids situated subdorsally just posterior to level of anus (Fig. $2 \mathrm{E})$.

$\mathrm{T}$ y $\mathrm{p}$ e $\mathrm{h}$ o s t: Myleus ternetzi (Norman) (Serrasalmidae, Characiformes).

$\mathrm{S}$ i t e : Intestine.

T y p e 1 o c a 1 i t y : Sinnamary River, French Guiana (10 November 1989).

E t y $\mathrm{m} \mathrm{o} 1$ o g y: The specific name annulata (= ringed) relates to a conspicuous annulation of cuticle in this nematode species.

D e p o s i t i o n of t y p e s : Holotype, allotype and paratypes in INPA (Cat. Nos. 017, 018, 019), paratypes (females) in UNSM (Cat. No. HWML 16337), and paratypes (male and females) in IPCAS (Cat. No. N-777).

Comments: The type and the only species of the genus Spinoxyuris was S. oxydoras Petter, 1994, described from the intestine of the thorny catfish, Oxydoras kneri Bleeker, from the Paraná River in Paraguay (Petter 1994). Although the gross morphology of $S$. annulata is similar to that of $S$. oxydoras, it differs from the latter in the absence of filaments on mature eggs, in a considerably longer spicule (66-72 $\mu \mathrm{m}$ vs. 35$40 \mu \mathrm{m}$ ), a more posterior situation of the unpaired postanal papilla in relation to the genital cone and the posterior ends of lateral alae, and in an approximately double length of the body (males $1.9 \mathrm{~mm}$, gravid females $4.0-4.4 \mathrm{~mm}$ vs. $1.0-1.1 \mathrm{~mm}$ and $1.9-2.4 \mathrm{~mm}$ ). Moreover, both species differ in the shape of the oral aperture (triangular vs. hexagonal). The female body of $S$. annulata is conspicuously annulated, which was not mentioned in the description of $S$. oxydoras. Both species also differ in the types of their hosts (pacus vs. catfishes) and in their geographical distribution. $S$. annulata is the first species of Spinoxyuris reported outside Paraguay and from French Guiana.

\section{Ichthyouris ovifilamentosa $\mathrm{sp}$. n. \\ Figs. 3, 4}

General: Small nematodes, males markedly smaller than females. Cuticle densely transversely striated. Narrow lateral alae initiating anteriorly near anterior extremity and extending posteriorly to caudal bursa in males and to level of anus in females. Oral aperture rectangular oblong, provided with six well-developed oral lamellae ( 2 dorsal, 2 ventral and 1 lateral on either side). Four lip-like formations present of which dorsal and ventral distinctly broader than both lateral. Four submedian cephalic papillae large, posteriorly elongated (as long as lip-like formations), situated in spaces between two neighbouring lip-like formations. Large amphids present on top of each lateral lip-like formation. Oesophagus formed by long, almost cylindrical corpus with slightly outlined "pharynx", very short isthmus and well-developed bulb provided 


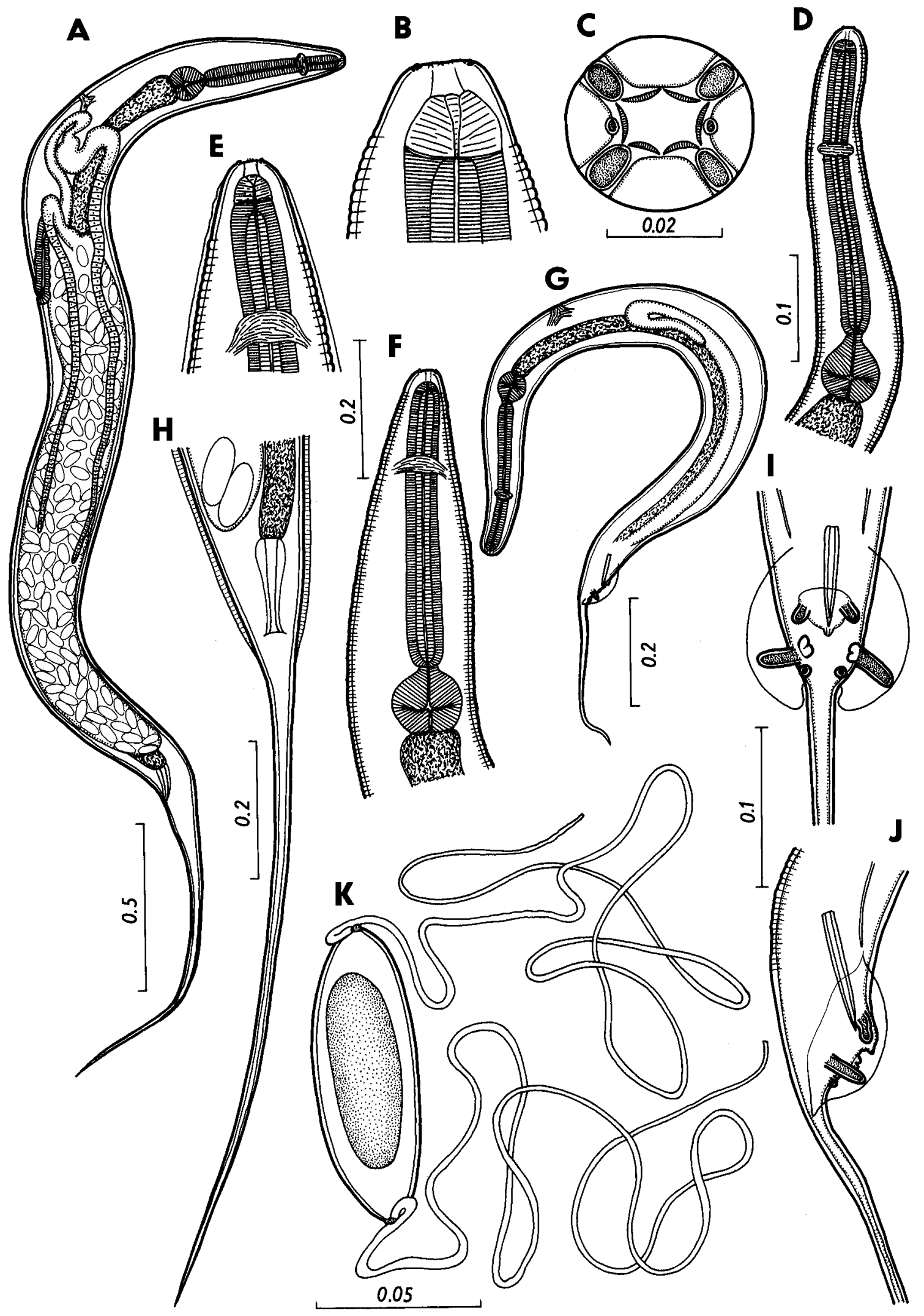

Fig. 3. Ichthyouris ovifilamentosa sp. n. A - gravid female, general view; $\mathbf{B}, \mathbf{C}$ - cephalic end of female, lateral and apical views; $\mathbf{D}$ - anterior end of male, lateral view; $\mathbf{E}, \mathbf{F}$ - anterior end of female, dorsoventral and lateral views; $\mathbf{G}$ - male, general view; $\mathbf{H}$ - caudal end of female, ventral view; I, $\mathbf{J}$ - cloacal region of male, ventral and lateral views; $\mathbf{K}$ - egg. Scales in $\mathrm{mm}$. 

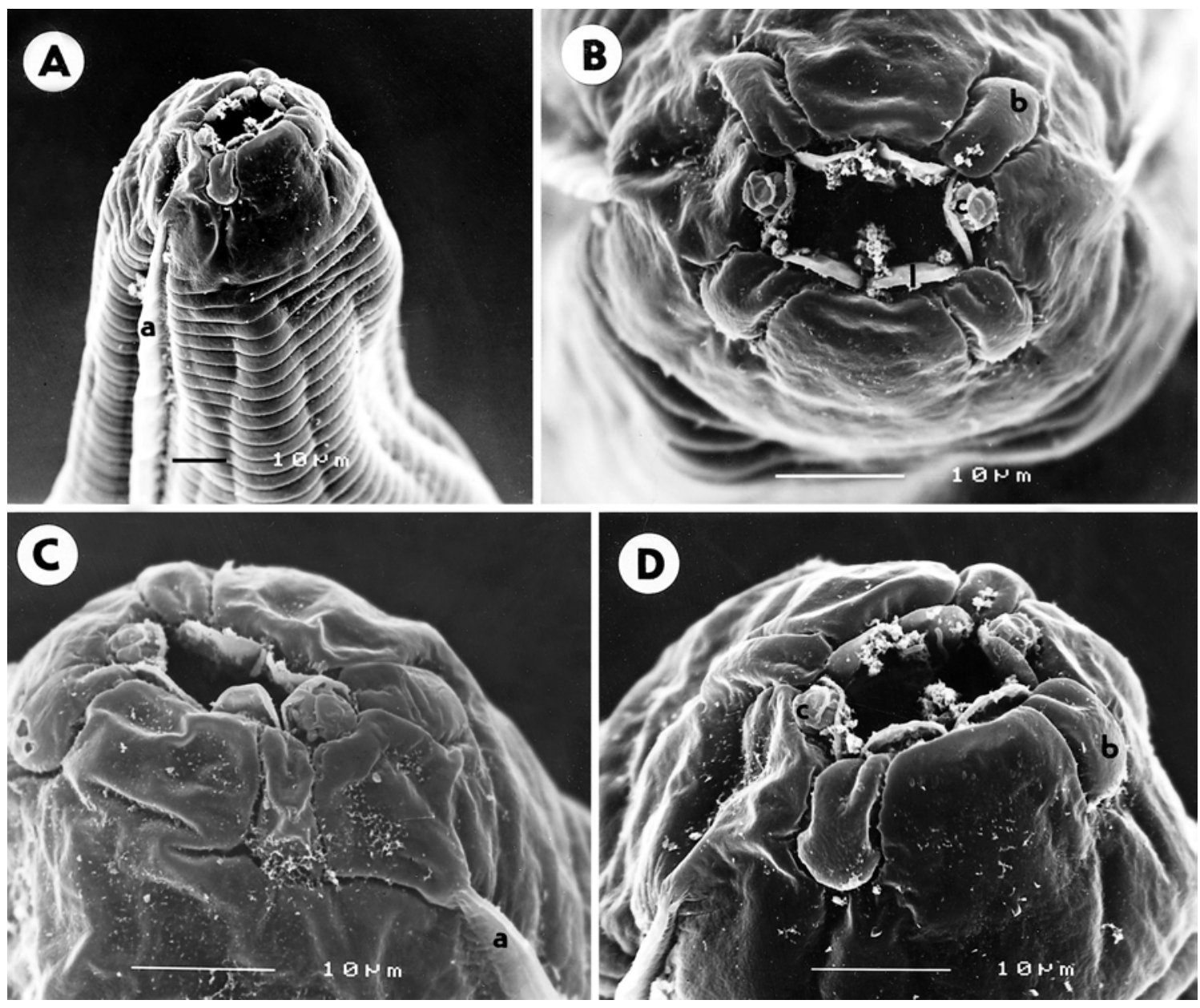

Fig. 4. Ichthyouris ovifilamentosa sp. n., scanning electron micrographs of female. A - anterior end of body, sublateral view; B cephalic end, apical view; C, D - cephalic end, subventral views (different specimens). a - lateral ala; b - cephalic papilla; c amphid; 1 - cephalic lamella.

with sclerotised apparatus. Nerve ring situated in anterior part of corpus, excretory pore some distance (equal to $44-52 \%$ of oesophagus in males and $31-46 \%$ of that in gravid females) posterior to oesophagus. Tail of both sexes forming very long, slender caudal spike.

Male (2 specimens; measurements of holotype in parentheses): Length of body including caudal spike 1,714-1,763 (1,714), maximum width 163 (163). Striae at middle part of body 3-6 (3) long. Entire oesophagus 384-396 (396) long; corpus including "pharynx" 312 327 (327) long and 27 (27) wide; isthmus 9-12 (9) long and 15-18 (15) wide; and bulb 60 (60) long and 63-69 (63) wide. Nerve ring and excretory pore 123 (123) and 571-585 (571), respectively, from anterior extremity. Genital cone rudimentary. Tail provided with relatively short, wide membranous lateral caudal alae forming a kind of bursa with rounded sides and forming distinct posterior lobes. Preanal papillae: one pair of large, elongate, posteriorly oriented papillae just anterior to level of cloacal opening. Postanal papillae: one pair of conspicuously large and long lateral papillae situated posterior to cloacal opening, being followed by pair of smaller subventral sessile papillae; in addition, pair of massive, strongly cuticularised bipartite plate-like structures present at inner base of long papillae. Caudal alae considerably exceeding anteriorly preanal papillae and posteriorly subventral postanal papillae. Single, well-sclerotised spicule 81-93 (93) and 6-9 (9) wide present, its distal tip pointed. Entire tail 324-420 (324) long; its broader anterior part 39-54 (39) long, length of slender caudal spike 285-366 (285). Tail forming 19$24 \%(19 \%)$ of entire length of body.

Female (10 gravid specimens; measurements of allotype in parentheses): Body elongate, cuticle densely transversely striated. Length of body including caudal spike 3,876-4,583 (4,352), maximum width 231-286 (272). Striae at middle part of body 3-9 (6-9) long. Lateral alae very narrow. Size of buccal cavity $12-15 \times$ 12-15 (15 × 12). Entire oesophagus 585-633 (585) long; corpus including "pharynx" 474-522 (474) long and 
60-63 (60) wide, "pharynx" 15-24 (24) long; isthmus 36 (6) long and 30-33 (33) wide; and bulb 99-105 (105) long and 120-129 (123) wide. Intestine narrow and straight. Nerve ring and excretory pore 132-150 (150) and 830-857 (857), respectively, from anterior extremity. Vulva situated 1,414-1,510 $(1,482)$ from anterior end of body, at 31-39 (34)\% of whole body length. Vulvar lips nonelevated. Muscular vagina short, directed anteriorly from vulva. Reproductive apparatus didelphic; both ovaries parallel, extending posteriorly far below level of vulva. Uteri containing numerous eggs occupying most space of body between vagina and end of intestine. Mature eggs elongate oval, thin-walled, not yet containing larva; each egg pole provided with small polar knob and one very long thread-like filament up to about $1.5 \mathrm{~mm}$ long; eggs 99-102 (99-102) long and 30-33 (30-33) wide. Entire tail 1,088-1,251 (1,115) long; its broader anterior part 165-272 (218), length of slender caudal spike 897-979 (897). Tail forming 26$28 \%(26 \%)$ of entire length of body.

T y p e host: Cichlasoma sp. (Cichlidae, Perciformes).

$\mathrm{S}$ i t e : Intestine.

T y p e 1 o c a 1 i t y : Negro River, São Gabriel da Cachoeira, Amazonas, Brazil (12 December 1989).

E t y m o 1 o g y: The specific name ovifilamentosa (= having filamented eggs) relates to the presence of egg filaments in this species.

D e p o s i t i o n of t y p e s: Holotype, allotype and paratypes in INPA (Cat. Nos. 020, 021, 022); paratypes (females) in UNSM (Cat. No. HWML 16338); and paratypes (male and females) in IPCAS (Cat. No. N-778).

Comments: The general morphology of this species, particularly the structure of the male caudal end, shows that it belongs to the genus Ichthyouris Inglis, 1962. At present Ichthyouris contains four species, all intestinal parasites of South American cichlids and catfishes: I. ro Inglis, 1962 (type species) from the cichlid Cichlasoma festivum (Heckel) in Guyana, I. brasiliensis Moravec, Kohn et Fernandes, 1992 from the armoured catfish Megalancistrus aculeatus (Perugia) in Brazil, I. laterifilamenta Moravec, Kohn et Fernandes, 1992 from the thorny catfish Trachydoras paraguayensis (Eigenmann et Ward) in Brazil, and I. bursata Moravec et Prouza, 1995 from the aquarium-reared discus Symphysodon discus Heckel (a fish of South American origin) in Europe (Inglis 1962, Moravec et al. 1992a, b, Moravec and Prouza 1995). In having only one filament on each egg pole, the new species distinctly differs from both congeners from catfishes, I. brasiliensis and I. laterifilamenta; moreover, female lateral alae of I. brasiliensis end posteriorly in distinct spines, whereas those of $I$. laterifilamenta initiate anteriorly far posterior to anterior extremity; both these species have a different structure of the male caudal end and I. laterifilamenta has a different type of cephalic papillae.

In contrast to $I$. ovifilamentosa, the female lateral alae of $I$. bursata initiate at the level of the nerve ring, the tail of both sexes is markedly shorter, and the structure of the male caudal end is different (a pair of massive, strongly cuticularised, plate-like structures is lacking).

Ichthyouris ovifilamentosa is most similar to I. ro, the only congeneric species in which a pair of strongly cuticularised plate-like structures on the male caudal end was reported. However, they differ in the structure of the cephalic end (mouth hexagonal, bounded by six lip-lobes, surrounded by four spherical cephalic papillae vs. mouth rectangular oblong, bounded by four liplobes, surrounded by four elongate cephalic papillae), in the position of the excretory pore (at the level of the oesophageal bulb vs. some distance posterior to the oesophagus), and in the length of the spicule (47-49 $\mu \mathrm{m}$ vs. 81-93 $\mu \mathrm{m})$; in addition, the eggs of $I$. ro are reported as embryonated, measuring only $36 \times 11 \mu \mathrm{m}$ and the presence of egg filaments is not mentioned.

\section{Ichthyouris sp.}

Figs. 5, 6

Description of female (10 gravid specimens): Small fusiform nematodes. Body including caudal spike 1,714-2,824 long and 231-354 wide. Cuticle between cephalic end and level of nerve ring with four markedly large transverse striae; rest of body with dense, fine transverse striations. Narrow lateral alae present, extending from level of nerve ring to anus; posterior ends of alae gradually narrowed. Oral aperture hexagonal, surrounded by three two-lobed lip-like structures, each lobe being provided with well-developed, rounded oral lamella. Four large spherical submedian cephalic papillae present, 2 on dorsal and 1 on each subventral lip-like structure (on 2 dorsal and 2 ventral lobes). Slightly smaller spherical lateral amphids present on lateral lobes of subventral lip-like formations. Lateral alae start anteriorly 99-120 from anterior extremity, their width at anterior part of body 21-27. Cuticular striae near anterior end of body 15-24 long, at middle of body 3-16 long. Size of buccal cavity 6-18 $\times 6-27$. Oesophagus formed by long cylindrical corpus with distinct short "pharynx", very short isthmus and welldeveloped bulb with sclerotised apparatus. Entire oesophagus 327-471 long; corpus including "pharynx" 222-348 long and 48-69 wide, length of "pharynx" 15; isthmus 3-6 long and 24-36 wide; bulb 93-120 long and 114-138 wide. Nerve ring and excretory pore 93-162 and 476-666, respectively, from anterior extremity (distance of excretory pore from oesophagus end equal to $36-71 \%$ of oesophagus length). Vulva situated 7341,142 from anterior end of body; vulvar lips not elevated. Muscular vagina short, directed anteriorly from vulva. Reproductive apparatus didelphic; both ovaries parallel, extending posteriorly far below level of vulva. Uteri containing numerous eggs occupying most space of body between vagina and the end of intestine. Mature eggs elongate oval, thin-walled, not yet containing larva; each egg pole provided with small polar knob 

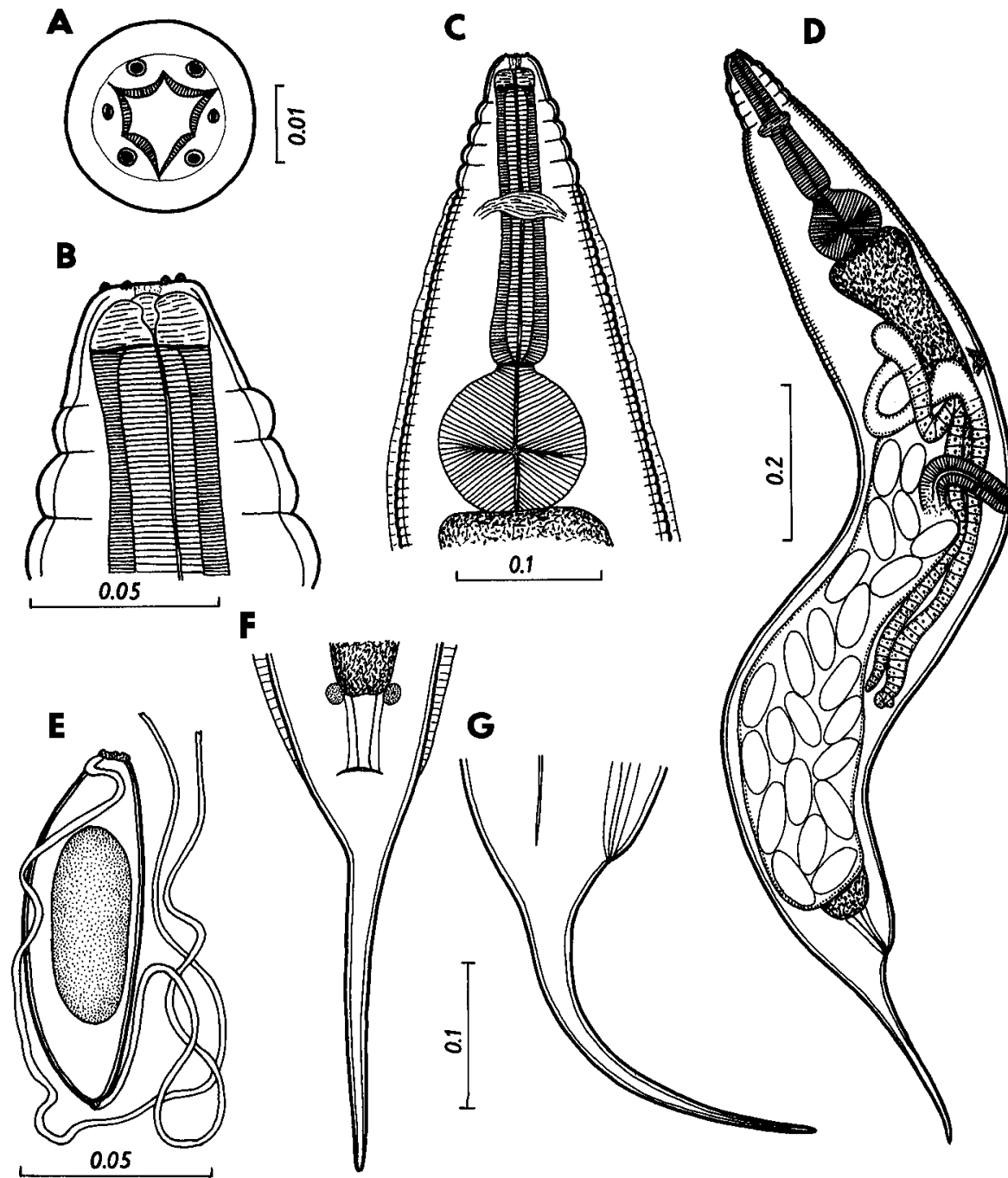

Fig. 5. Ichthyouris sp. from Cichlasoma sp., gravid female. A, B - cephalic end, apical and lateral views; $\mathbf{C}-$ anterior end of body, dorsoventral view; D - gravid female, general view; $\mathbf{E}$ - egg; F, G - tail, ventral and lateral views. Scales in $\mathrm{mm}$.

(usually one distinctly broader than that on the opposite pole) and one very long thread-like filament. Entire tail 294-342 long; its broader anterior part 45 long, length of slender caudal spike 249-297. Tail forming $15-17 \%$ of entire length of body.

H o s t: Cichlasoma sp. (Cichlidae, Perciformes).

$\mathrm{S}$ i t e : Intestine.

L o c a 1 i t y : Negro River, São Gabriel da Cachoeira, Amazonas, Brazil (12 December 1989).

De p o s i ti o n of s p e c i m e n s : INPA (Cat. No. 023); UNSM (Cat. No. HWML 16339); and IPCAS (Cat. No. N779).

Comments: Although only females are available, their general morphology (especially the structure of the cephalic end and the oesophagus, the character of eggs, and the position of ovaries) shows that they undoubtedly belong to Ichthyouris. Of other pharyngodonid genera from neotropical fishes, females of Cosmoxynema, Cosmoxynemoides, Parasynodontis and Travnema can be easily distinguished from those of Ichthyouris by the shape of the oesophagus as well as by the structure of the cephalic end (Moravec et al. 1992a, b, 1994, Moravec 1998); the shape of the oesophagus of Brasilnema and Spinoxyuris is similar, but in both these genera the ends of ovaries are directed anteriorly and posteriorly, as opposed to ovaries with both ends directed posteriorly in Ichthyouris. Another genus, represented by the species Laurotravassoxyuris bravoae Osorio-Sarabia, 1984, was reported from neotropical freshwater fishes; however, a recent re-examination of its type specimens revealed that it did not belong to the Pharyngodonidae but, in fact, to the cosmocercoid genus Atractis Dujardin, 1845 (see Moravec 2000). 

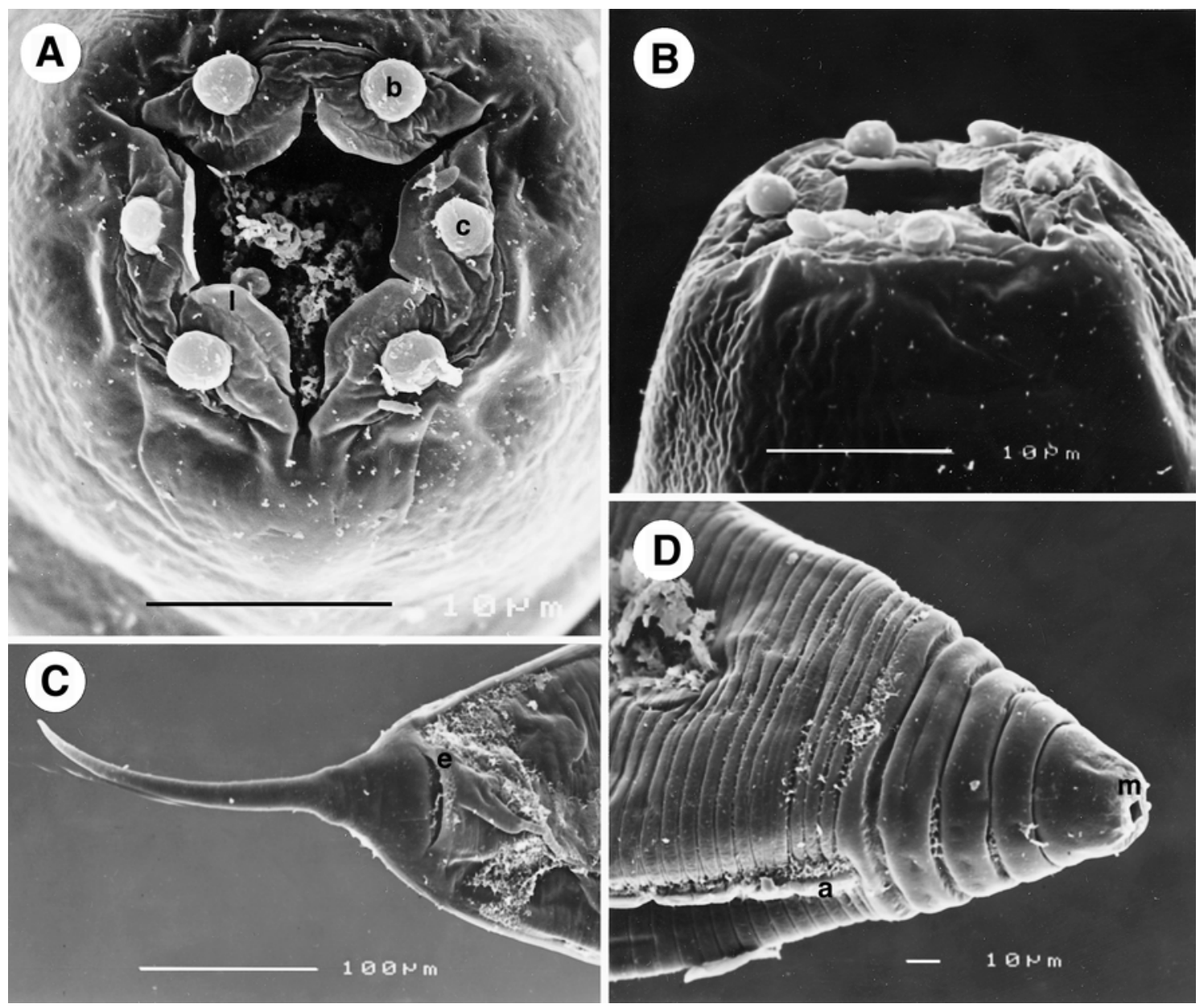

Fig. 6. Ichthyouris sp. from Cichlasoma sp., scanning electron micrographs of female. A - cephalic end, subventral view; B cephalic end, lateral view; $\mathbf{C}$ - caudal end, ventral view; D - anterior end of body, sublateral view. a - lateral ala; b - cephalic papilla; c-amphid; e - anus; 1 - cephalic lamella; $\mathrm{m}$ - mouth.

By its characteristic annulation on the female cephalic end, this species distinctly differs from all hitherto known species of Ichthyouris and may well represent a new species. However, since no males are available, we refrain from formally establishing it. In having only one long filament on each egg pole, this species resembles two other congeneric species from cichlids, I. bursata and I. ovifilamentosa; in the third species from cichlids, I. ro, egg filaments are not mentioned, but the small measurements of eggs suggest that only immature eggs were studied.

Females of Ichthyouris sp. occurred in the same host fish as I. ovifilamentosa. Both species were easily distinguished even at a low magnification under the dissecting microscope by the shape of the body and the length of the caudal spike.

Acknowledgements. The authors' thanks are due to the staff of the Laboratory of Electron Microscopy of the Institute of Parasitology, ASCR, in České Budějovice, for their technical assistance and to Mrs. I. Husáková from the Laboratory of Helminthology of the same institute for the help with preparation of illustrations. Thanks are also extended to Dr. Michel Jégu of the Museum National d'Histoire Naturelle, Paris, France, for providing and identifying the host fish from French Guiana. This work was supported by the grant No. A6022901 from the Grant Agency of the Academy of Sciences of the Czech Republic. 


\section{REFERENCES}

INGLIS W.G. 1962: Ichthyouris ro gen. et sp. nov (Nematoda): an oxyurid from a freshwater fish. J. Helminthol. 36: 45-50.

FERNANDES M.T., ARTIGAS P.T., CAMPOS M.S. 1983: Travnema araujoi $\mathrm{n}$. sp. (Nematoda, Pharyngodonidae), parasito de Curimatus gilberti Quoy \& Gaimard (Pisces, Characinidae). Rev. Fac. Med. Vet. Zool. Univ. São Paulo 20: 35-41.

MORAVEC F. 1998: Nematodes of Freshwater Fishes of the Neotropical Region. Academia, Praha, 464 pp.

MORAVEC F. 2000: Systematic status of Laurotravassoxyuris bravoae Osorio-Sarabia, 1984 (Nematoda: Pharyngodonidae) [= Atractis bravoae (Osorio-Sarabia, 1984) n. comb.: Cosmocercidae]. Syst. Parasitol. 46: 117 122.

MORAVEC F., KOHN A., FERNANDES B.M.M. 1992a: Three new species of oxyuroid nematodes, including two new genera, from freshwater catfishes in Brazil. Syst. Parasitol. 21: 189-201.

MORAVEC F., KOHN A., FERNANDES B.M.M. 1992b: Nematode parasites of fishes of the Paraná River, Brazil. Part 1. Trichuroidea, Oxyuroidea and Cosmocercoidea. Folia Parasitol. 39: 327-353.

Received 18 January 2001
MORAVEC F., KOHN A., FERNANDES B.M.M. 1994 : Structure of the cephalic end of two little-known oxyuroid genera, Travnema Pereira, 1938 and Cosmoxynemoides Travassos, 1949, parasites of fishes, as revealed by SEM. J. Helminthol. 68: 319-322.

MORAVEC F., PROUZA A. 1995: Ichthyouris bursata sp. n. (Nematoda: Oxyuroidea) from an aquarium-reared discus, Symphysodon discus (Pisces), in Europe. Parasite 2: 385390.

PEREIRA C. 1938: Travnema travnema n. gen. n. sp. (Nematoda: Oxyuridae) parasito de Curimatus elegans (Pisces: Characinidae) no Nordeste Brasileiro. Livro Jubilar do Dr. Lauro Travassos, pp. 381-385.

PETTER A.-J. 1994: Nématodes de Poissons de Paraguay. VII. Oxyuroidea: Spinoxyuris oxydoras n. g., n. sp. Rev. Suisse Zool. 101: 761-769.

TRAVASSOS L. 1949: Contribuição ao conhecimento da fauna helmintológica dos peixes de água doce do Brasil. IV. Dois novos generos de Cosmocercidae (Nematoda) e uma nota helmintológica. Mem. Inst. Oswaldo Cruz 46: 633-637.

Accepted 12 March 2001

\section{ADDENDUM}

Quite recently Martins et al. (2001) have established an additional new species of Ichthyouris, I. voltagrandensis Martins, Yoshitoshi et Umekita, 2001, from the intestine of Myleus tiete Eigenmann et Norris (Serrasalmidae: Characiformes) in Brazil. It differs from all congeners, including I. ovifilamentosa, in having two long filaments on one egg pole.

MARTINS M.L., YOSHITOSHI E.R., UMEKITA H. 2001: Ichthyouris voltagrandensis $\mathrm{n}$. sp. (Nematoda: Pharyngodonidae) from Myleus tiete Eigenmann \& Norris, 1900
(Osteichthyes: Characidae) in the Volta Grande Reservoir, MG, Brazil. Rev. Bras. Biol. 61: 305-310. 